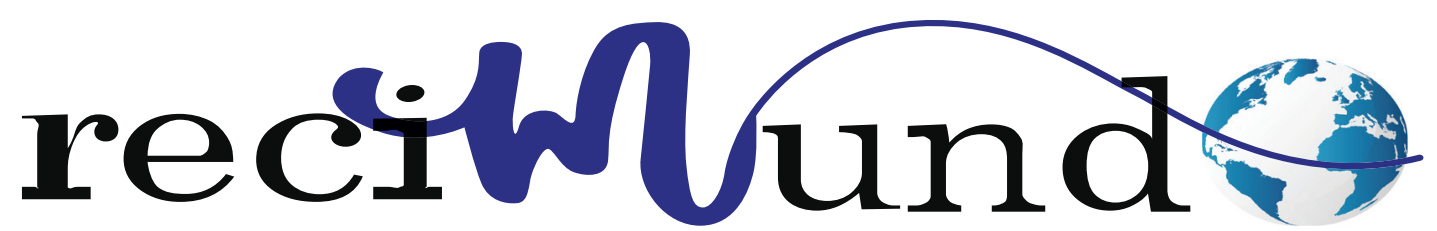

Revista Científica Mundo de la Investigación y el Conocimiento

DOI: 10.26820/recimundo/4.(1).enero.2020.296-305

URL: http://recimundo.com/index.php/es/article/view/724

EDITORIAL: Saberes del Conocimiento

REVISTA: RECIMUNDO

ISSN: 2588-073X

TIPO DE INVESTIGACIÓN: Artículo de Revisión

CÓDIGO UNESCO: 3201 Ciencias Clínicas; 3201.11 Radiología PAGINAS: 296-305

\title{
Tratamiento quirúrgico del quiste sinovial en muñeca
}

\section{Surgical treatment of synovial cyst in wrist \\ Tratamento cirúrgico do cisto sinovial no punho}

Maria Fernanda Zambrano Castro1; Johanna Rosario Orellana Rodriguez²; Francisco Antonio Rambay Ayala3;

Sally Estefania Ronquillo del Pozo ${ }^{4}$

RECIBIDO: 18/09/2019 ACEPTADO: 29/10/2019 PUBLICADO: 31/01/2020

1. Médico; Investigador Independiente; Guayaquil, Ecuador; mazambranoc@uees.edu.ec; (D) https://orcid. org/0000-0001-6278-8209

2. Médico; Investigador Independiente; Guayaquil; johasky8@gmail.com; (D) https://orcid.org/0000-0001-79617545

3. Médico; Investigador Independiente; Guayaquil, Ecuador, ciscoantonio@hotmail.com; (D) https://orcid. org/0000-0002-7405-1869

4. Médico; Investigador Independiente; Guayaquil, Ecuador, sallyeronquillo1990@gmail.com; (D) https://orcid. org/0000-0002-5779-9509

CORRESPONDENCIA

Maria fernanda Zambrano Castro

mazambranoc@uees.edu.ec

Guayaquil, Ecuador

○ RECIMUNDO; Editorial Saberes del Conocimiento, 2020 


\section{RESUMEN}

Los quistes sinoviales o gangliones, son definidos como masas (protuberancias) muy comunes, que algunas veces crecen en la mano y en la muñeca. Estos nódulos se encuentran generalmente en la parte superior de la muñeca, lado palmar de la misma, en la última articulación de un dedo, (quiste mucoso) o en la base de un dedo. Usualmente se forman de articulaciones vecinas o vainas tendíneas; no obstante, no existe alguna causa definida. Estos quistes pueden ser dolorosos, más aún, cuando están apareciendo o mantienen el uso constante y demandante de la mano. Son conocidos también, con el nombre de gangliones y cambian constantemente de tamaño y no son malignos (cancerosos). Su diagnóstico va a depender del lugar dónde esté ubicado y el aspecto que éste tenga. De manera general, el médico tratante indica hacer una radiografía, con el fin de descartar lesiones en las articulaciones vecinas. Su tratamiento, podría ser simplemente la observación de cualquier cambio. Sin embargo, si el quiste es doloroso, limita la actividad, o su apariencia es inaceptable al paciente, se podría recomendar otro tratamiento, como por ejemplo: incluir la eliminación del fluido del quiste aspirándolo con una aguja y/o el uso de una férula o splint para evitar el movimiento. Si estos tratamientos no quirúrgicos fallan, su cirujano de mano podría recomendarle una cirugía para eliminar el quiste. El objetivo de la cirugía es eliminar el origen del quiste, para lo que se podría requerir de la extracción de un trozo de cápsula articular o de vaina tendínea cercana al ganglión. Si el ganglión es extraído de la muñeca, es posible recomendar una férula o splint para el período post operatorio. Algunos pacientes pueden sentir dolor, molestias e inflamación en el sitio de la cirugía, algún tiempo más prolongado que otros.

Palabras clave: Tratamiento Quirúrgico, Quiste Sinovial, Ganglión, Cápsula Articular, Nódulos.

\section{ABSTRACT}

Synovial cysts or ganglions are defined as very common masses (bumps), which sometimes grow in the hand and wrist. These nodules are usually found in the upper part of the wrist, palmar side of the wrist, in the last joint of a finger, (mucous cyst) or at the base of a finger. They are usually formed from neighboring joints or tendon sheaths; However, there is no definite cause. These cysts can be painful, even more so, when they are appearing or maintain the constant and demanding use of the hand. They are also known, with the name of ganglions and constantly change in size and are not malignant (cancerous). Your diagnosis will depend on where you are located and what it looks like. In general, the attending physician indicates to do an x-ray, in order to rule out lesions in the neighboring joints. Your treatment could simply be the observation of any changes. However, if the cyst is painful, limits the activity, or its appearance is unacceptable to the patient, another treatment might be recommended, such as: including removing the cyst fluid by aspirating it with a needle and / or using a splint. or splint to prevent movement. If these non-surgical treatments fail, your hand surgeon may recommend surgery to remove the cyst. The objective of the surgery is to eliminate the origin of the cyst, which may require the removal of a piece of joint capsule or tendon sheath near the ganglion. If the ganglion is removed from the wrist, it is possible to recommend a splint or splint for the post operative period. Some patients may feel pain, discomfort and inflammation at the surgery site, some time longer than others.

Keywords: Surgical Treatment, Synovial Cyst, Ganglion, Articular Capsule, Nodules.

\section{RESUMO}

Cistos ou gânglios sinoviais são definidos como massas muito comuns (inchaços), que às vezes crescem na mão e no pulso. Esses nódulos geralmente são encontrados na parte superior do punho, no lado palmar do punho, na última articulação de um dedo (cisto mucoso) ou na base de um dedo. Eles são geralmente formados a partir de articulações vizinhas ou bainhas de tendões; No entanto, não há causa definida. Esses cistos podem ser dolorosos, ainda mais quando estão aparecendo ou mantêm o uso constante e exigente da mão. Eles também são conhecidos, com o nome de gânglios e mudam constantemente de tamanho e não são malignos (cancerígenos). Seu diagnóstico dependerá de onde você está localizado e de como ele se parece. Em geral, o médico assistente indica fazer um raio-x, a fim de descartar lesões nas articulações vizinhas. Seu tratamento pode ser simplesmente a observação de quaisquer alterações. No entanto, se o cisto é doloroso, limita a atividade ou sua aparência é inaceitável para o paciente, outro tratamento pode ser recomendado, como: incluindo a remoção do líquido do cisto, aspirando-o com uma agulha e / ou usando uma tala. ou tala para impedir o movimento. Se esses tratamentos não cirúrgicos falharem, seu cirurgião de mão pode recomendar uma cirurgia para remover o cisto. O objetivo da cirurgia é eliminar a origem do cisto, o que pode exigir a remoção de um pedaço da cápsula articular ou da bainha do tendão próximo ao gânglio. Se o gânglio for removido do pulso, é possível recomendar uma tala ou tala para o período pós-operatório. Alguns pacientes podem sentir dor, desconforto e inflamação no local da cirurgia, mais algum tempo do que outros.

Palavras-chave: Vesícula biliar, bílis, Situs Inversus, colecistectomia laparoscópica. 


\section{Introducción}

Los quistes dorsales de la muñeca, se deben de manera general a una patología capsular. Dicha anomalía, consiste en la formación de pseudoquistes de degeneración mixoide que habitualmente, se localizan al nivel del ligamento escafolunar. (Peláez, 2017, pág. 18). Para su cura, han sido propuestos distintos tratamientos, los cuales van desde la abstención completa, hasta la cirugía a cielo abierto. De manera general, se ha podido observar que el tratamiento quirúrgico ante esta enfermedad es el ha predominado como más curativo; no obstante, es también el responsable de numerosas complicaciones: que van desde cicatrices antiestéticas, neuromas y pérdida de movilidad articular. (Peláez, 2017, pág. 18)

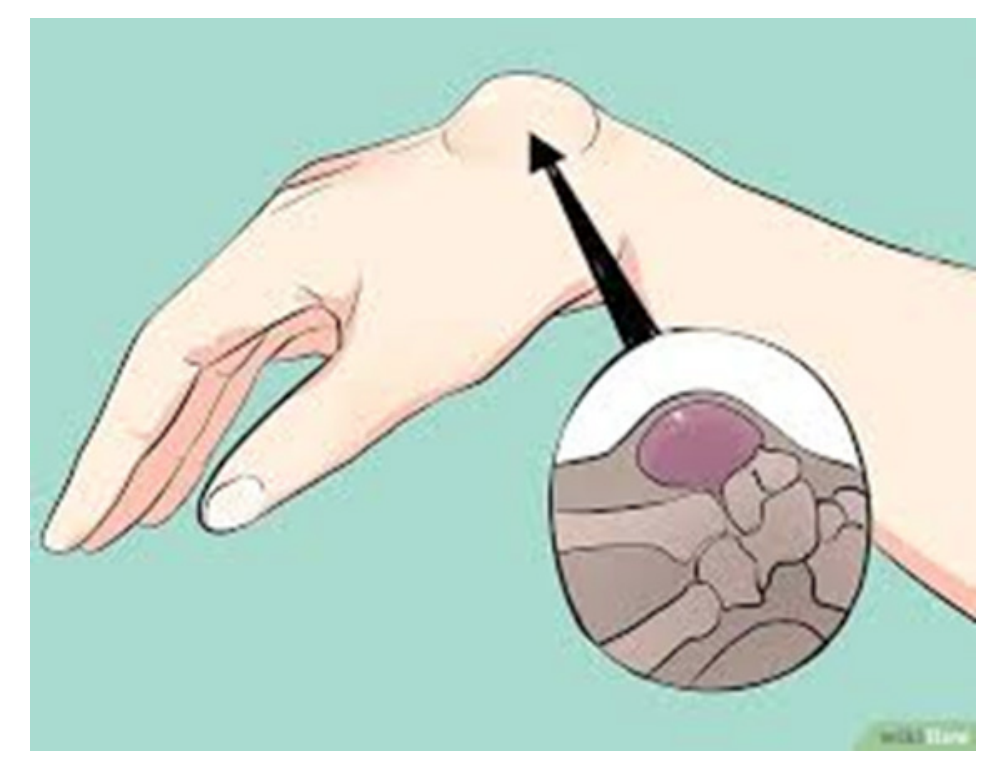

Figura 1. Quiste Sinovial

Fuente: (Peláez, 2017)

Asimismo, es importante señalar que los quistes sinoviales, gangliones por los anglosajones, son los tumores más frecuentes de la mano, los mismos están representados en grandes series. (Peláez, 2017, pág. 19) Varios tratamientos han sido propuestos, éstos van desde la abstención terapéutica hasta la cirugía a cielo abierto, comprendiendo: la exceresis simple del quiste, y/o asociada a una porción de cápsula articular adyacente.

Estudios ratifican que, el tratamiento quirúrgico, pudiera ser el más efectivo, sin embargo, es también el responsable de numerosos problemas, tales como cicatriz antiestética, lesiones sobre la rama sensitiva del nervio radial y rigidez de muñeca, sobre todo una pérdida de la flexión. (Peláez, 2017, pág. 18). De allí, que la resec- ción artroscópica de los quistes sinoviales dorsales de muñeca, pareciera ser el método de elección, debido al post operatorio extremadamente simple, la ausencia de las complicaciones descriptas y el bajísimo índice de recidivas. 


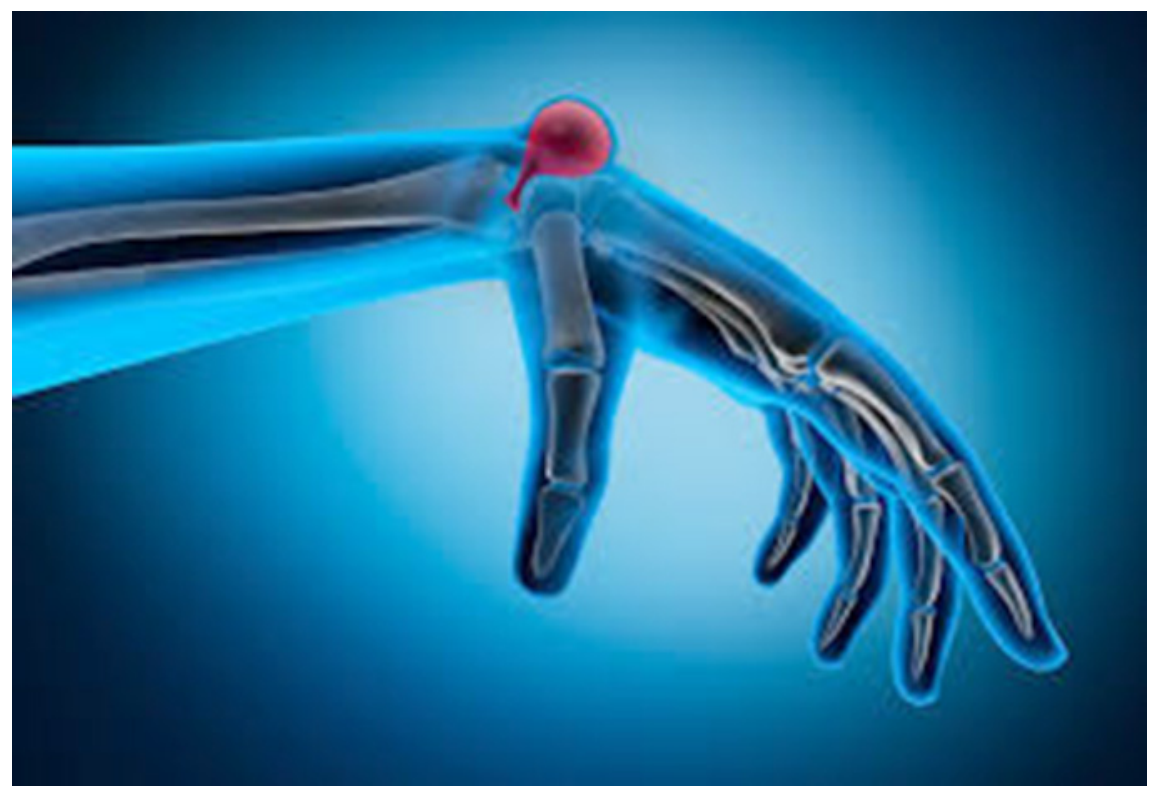

Figura 2. Quiste Sinovial

Fuente: (Peláez, 2017)

De manera importante se debe destacar que, los quistes sinoviales de la muñeca pueden aparecer de manera espontánea como lo puede indicar un diagnóstico frecuente. Sin embargo, ellos según (Seguerí, 2016, pág. 13), pueden aparecer también luego de un traumatismo o de una caída encima de la mano, aparentemente sin gravedad. Un quiste sinovial puede surgir a cualquier edad tanto en hombres como mujeres.

En la mayoría de los casos los quistes artro-sinoviales de la muñeca no tienen una causa precisa. En esos casos son llamados quistes esenciales (típicos) o de causa desconocida o idiopática. Sin embargo, ellos pueden asociarse con patologías osteo-articulares: hiperlaxidad de la muñeca, esguince grave de la muñeca o artrosis de la muñeca. En la mayoría de los casos, los quistes sinoviales son asintomáticos. (Seguerí, 2016, pág. 13), Esto quiere decir que ellos no causan ninguna molestia en el paciente, lo cual conlleva a una ausencia de tratamiento. Es estos casos la cirugía de la muñeca no es necesaria.

No obstante, un quiste sinovial puede en otros casos ser la causa de dolores en la muñeca o de disminución de la fuerza o de la movilidad, particularmente cuando se necesita realizar gestos de amplitud articular de la muñeca. Estos quistes sintomáticos (dolorosos) pueden ser operados con asistencia artroscópica. Para ello se necesita realizar una cirugía de la mano altamente especializada. (Osses, Muñoz Ch, \& Astudillo $A, 2009$ )

El quiste sinovial puede aparecer delante de la muñeca o encima de su pliegue de flexión. A este se le llama quiste sinovial palmar. Los quistes sinoviales pueden aparecer también detrás de la muñeca. En estos casos hablamos de quiste sinovial dorsal. Pero en otros casos el quiste sinovial puede ser también invisible y presentar un dolor aislado en la muñeca. Durante el examen se tratará de buscar una causa de traumatismo en la muñeca. (Seguerí, 2016, pág. 14),

\section{Metodología}

\section{Fuentes documentales}

El análisis correspondiente a las características que predomina en el tema seleccionado, llevan a incluir diferentes fuentes documentales encargadas de darle el respectivo apoyo y en ese sentido cumplir con la valoración de los hechos a fin de generar nue-

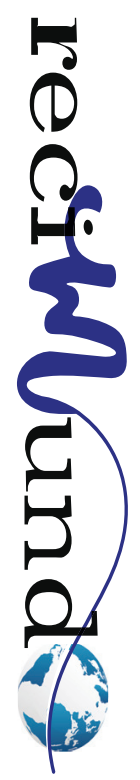


vos criterios que sirven de referencia a otros procesos investigativos. Para (Arias, 2010), las fuentes documentales incorporadas en la investigación documental o bibliográfica, "representa la suma de materiales sistemáticos que son revisados en forma rigurosa y profunda para llegar a un análisis del fenómeno". (p.41). Por lo tanto, se procedió a cumplir con la realización de una lectura previa determinada por encontrar aquellos aspectos estrechamente vinculados con el "TRATAMIENTO QUIRÚRGICO DEL QUISTE SINOVIAL EN MUÑECA" para luego explicar mediante un desarrollo las respectivas apreciaciones generales de importancia.

\section{Técnicas para la Recolección de la Infor- mación}

La conducción de la investigación para ser realizada en función a las particularidades que determinan a los estudios documentales, tiene como fin el desarrollo de un conjunto de acciones encargadas de llevar a la selección de técnicas estrechamente vinculadas con las características del estudio. En tal sentido, (Arias 2010) refiere, que es "una técnica particular para aportar ayuda a los procedimientos de selección de las ideas primarias y secundarias". (p. 71). Por ello, se procedió a la utilización del subrayado, resúmenes, fichaje, como parte básica para la revisión y selección de los documentos que presentan el contenido teórico. Es decir, que mediante su aplicación de estas técnicas se pudo llegar a recoger informaciones en cuanto a la revisión bibliográfica de los diversos elementos encargados de orientar el proceso de investigación.

Tal como lo expresa, (Dávila, 2010, pág. 98) "las técnicas documentales proporcionan las herramientas esenciales y determinantes para responder a los objetivos formulados y llegar a resultados efectivos" (p. 58). Es decir, para responder con eficiencia a las necesidades investigativas, se introdujeron como técnica de recolección el método inductivo, que hizo posible llevar a cabo una valoración de los hechos de forma particu- lar para llegar a la explicación desde una visión general. Asimismo, se emplearon las técnicas de análisis de información para la realización de la investigación que fue ejecutada bajo la dinámica de aplicar diversos elementos encargados de determinar el camino a recorrer por el estudio,

Según (Dávila, 2010, pág. 99) las técnicas de procesamiento de datos en los estudios documentales "son las encargadas de ofrecer al investigador la visión o pasos que debe cumplir durante su ejercicio, cada una de ellas debe estar en correspondencia con el nivel a emplear" (p. 123). Esto indica, que para llevar a cabo el procesamiento de los datos obtenidos, es necesario establecer las técnicas que serán seleccionadas, destacándose en este caso, de manera particular: fichas de resumen, textual, registros descriptivos entre otros, los mismos se deben ajustar al nivel que ha sido seleccionado.

\section{Resultados}

\section{Quistes Sinoviales}

El tumor más frecuente de la mano, es el quiste sinovial de la bolsa serosa sinovial de la muñeca. (Posada, 2019, pág. 25). Esta lesión, se presenta a cualquier edad y en ambos sexos, su etiología no es clara, pero se reconoce con mayor frecuencia en el dorso de la muñeca de mujeres entre los $11 \mathrm{y}$ 35 años de edad con antecedente de algún traumatismo. En la mayoría de los casos el paciente solicita atención por razones estéticas y en 25 a $67 \% 4$ se presentan síntomas como dolor, disminución de la fuerza y parestesias. (Posada, 2019, pág. 26) 


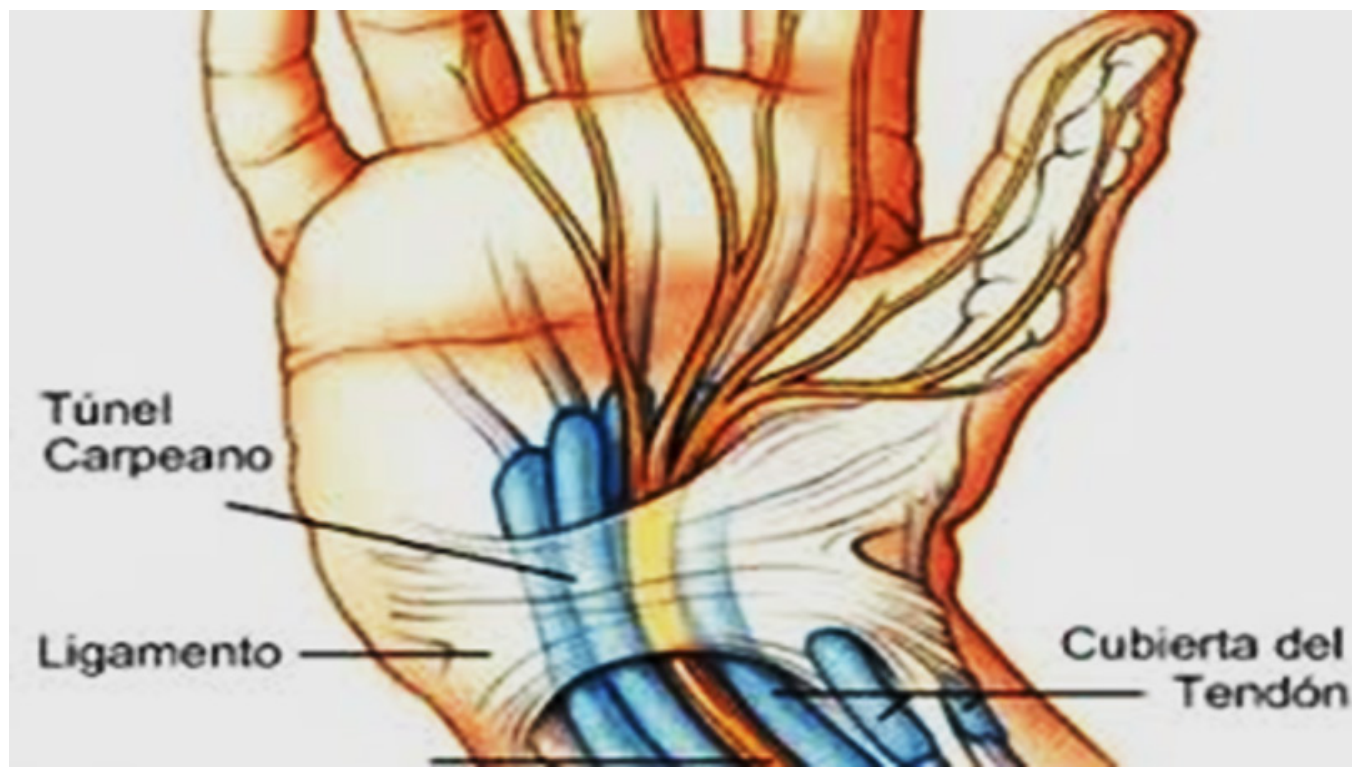

Figura 3. Estructura Interna de la Muñeca

Fuente: (Posada, 2019)

Es de mencionar que, han sido utilizados diversos tratamientos en los cuales predomina el hecho de mantener vigilancia para esperar la remisión espontánea, compresión, ruptura con un golpe o punciones, aplicación de suturas, infiltración de fármacos como triamcinolona, hidrocortisona, metilprednisolona y la extirpación quirúrgica bajo anestesia local, regional o general; con y $\sin$ isquemia; esto, debido a que, con cualquiera de los tratamientos mencionados hay probabilidad de recidiva. (Medline, 2018)

Por ende, los quistes dorsales de la muñeca, son generalmente debidos a una patología capsular, dicha anomalía; consiste en la formación de pseudoquistes de degeneración mixoide que habitualmente, se localizan al nivel del ligamento escafolunar. Los mismos, pueden aparecer de manera espontánea como lo puede indicar un diagnóstico frecuente. Sin embargo, ellos pueden aparecer también luego de un traumatismo o de una caída encima de la mano, aparentemente sin gravedad. (Martínez Roncal, Elena Salcedo, \& Salcedo, 2009)

Del mismo modo, se debe entender que un quiste sinovial puede surgir a cualquier edad tanto en hombres como mujeres. En esos casos son llamados quistes esenciales (típicos) o de causa desconocida o idiopática. Sin embargo, ellos pueden asociarse con patologías osteo-articulares: hiperlaxidad de la muñeca, esguince grave de la muñeca o artrosis de la muñeca. En la mayoría de los casos, los quistes sinoviales son asintomáticos. Esto quiere decir que ellos no causan ninguna molestia en el paciente, lo cual conlleva a una ausencia de tratamiento. Fuente: (Posada 2019, 32)

Es estos casos, cuando la cirugía de la muñeca no es necesaria. No obstante, un quiste sinovial puede en otros casos ser la causa de dolores en la muñeca o de disminución de la fuerza o de la movilidad, particularmente cuando se necesita realizar gestos de amplitud articular de la muñeca. Estos quistes sintomáticos (dolorosos), según (Posada, 2019), "pueden ser operados con asistencia artroscópica", para ello se necesita realizar una cirugía de la mano altamente especializada.

Del mismo modo, hay que tener presente que el quiste sinovial puede aparecer delante de la muñeca o encima de su pliegue de flexión. A este se le llama quiste sinovial palmar. Los quistes sinoviales pueden aparecer también detrás de la muñeca. En

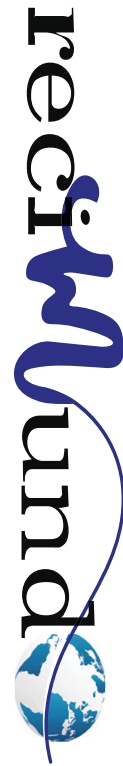


estos casos hablamos de quiste sinovial dorsal. Pero en otros casos el quiste sinovial puede ser también invisible y presentar un dolor aislado en la muñeca.

Durante el examen se tratará de buscar una causa de traumatismo en la muñeca. El examen clínico a criterio de (Posada 2019, p.33), "estudiará los signos de hiperlaxidad de la muñeca, una limitación de las amplitudes y / o de la fuerza de la muñeca, así como una sinovitis dorsal de los extensores a menudo asociada". El único examen complementario y necesario en un quiste sino- vial de la muñeca es una radiografía simple.

Este tipo de examen será prescrito con la intención de buscar y descartar una patología óseo-articular subyacente. De allí, que para (Posada, 2019 p. 25), "la ecografía de la muñeca es prácticamente de poco interés a pesar de que en algunos casos es prescrita". He . aquí, que los quistes sinoviales palmares provienen a menudo de la articulación radiocarpiana de la muñeca. Asimismo, los quistes dorsales de la muñeca son a menudo de origen mediocarpiano.

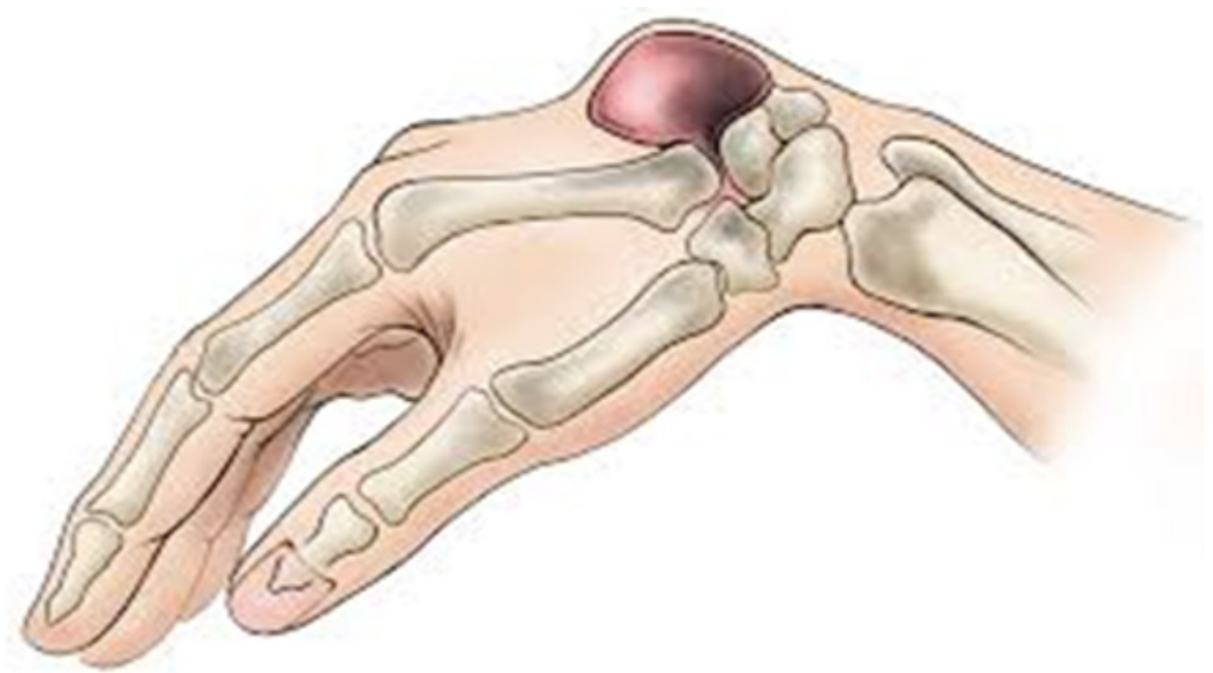

Figura 4. Quiste ganglionar de la muñeca y mano

Fuente: (Posada, 2019)

Para la cura de esta patología según (Posada, 2019, pág. 15), "se han propuesto varios tratamientos, los mismos van desde la abstención teraupéutica hasta la cirugía a cielo abierto, comprendiendo: la exceresis simple del quiste, y/o asociada a una porción de cápsula articular adyacente".
De esta manera, el tratamiento quirúrgico, pareciera ser el más efectivo, sin embargo, es también el responsable de numerosos problemas, tales como cicatriz antiestética, lesiones sobre la rama sensitiva del nervio radial y rigidez de muñeca, sobre todo una pérdida de la flexión.

Tabla 1. Ubicación del quiste sinovial

\begin{tabular}{|l|c|r|}
\hline SITIO & CASOS & \% \\
\hline Dorso de muñeca derecha & 27 & 39.1 \\
Dorso de muñeca izquierda & 23 & 13.3 \\
Cara anterior muñeca derecha & 11 & 15.9 \\
Cara anterior muñeca izquierda & 6 & 8.6 \\
Borde radial muñeca derecha & 1 & 1.4 \\
Borde radial muñeca izquierda & 1 & 1.4 \\
Total & 69 & 100 \\
\hline
\end{tabular}

Fuente: (Posada, 2019) 
Se puede decir entonces que, la artroscopia de la muñeca es un procedimiento quirúrgico donde el médico puede trabajar dentro de la articulación sin tener que abrir el área. Consiste en realizar dos pequeños orificios donde por uno, se ingresa una cámara de televisor con una óptica de apenas $2.7 \mathrm{mi}-$ límetros y, por el otro, el instrumento que se utilizará para llevar a cabo la operación. Es una intervención muy versátil pues sirve para reconstruir muchas estructuras rotas o quebradas (ya sea hueso o ligamentos), que fueron previamente observadas a través de radiografías, scanner o resonancia. (Clinica Davila, 2018)

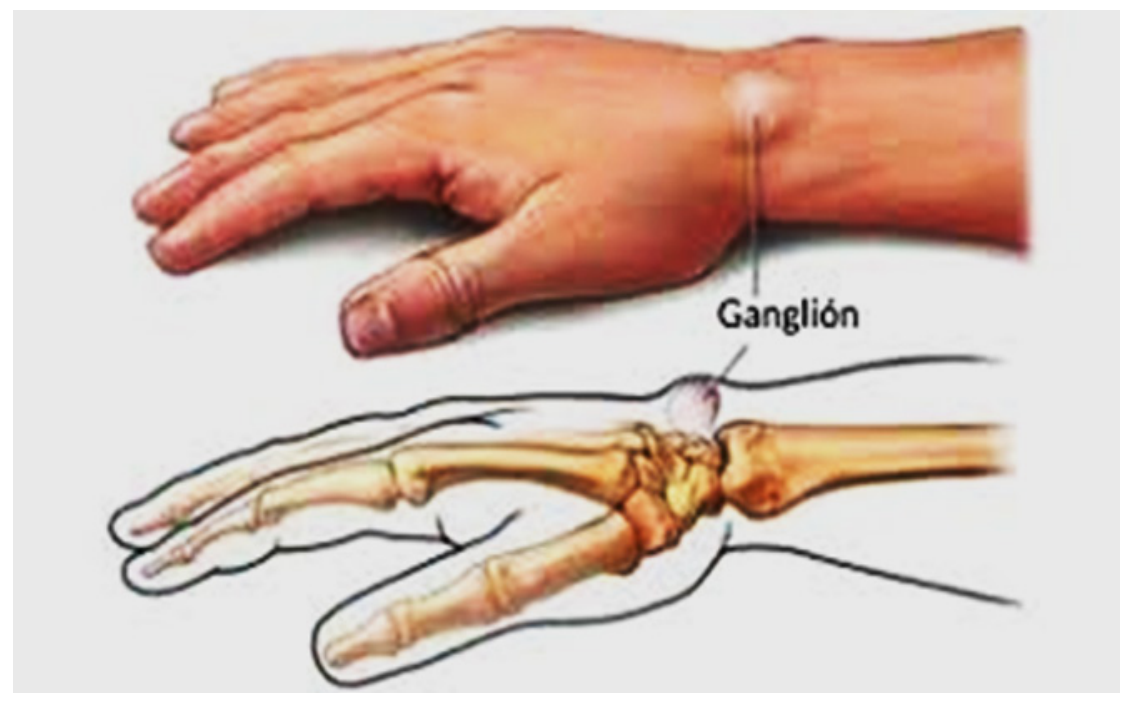

Figura 5. Artroscopia de Muñeca

Fuente: (Posada, 2019)

La imagen descrita permite reconocer que, el quiste sinovial corresponde a una hernia de la articulación de la muñeca. En este tipo de lesión, la cápsula y la sinovial constituyen una membrana que mantiene el líquido articular en la articulación de la muñeca. Esta membrana se comporta como una bolsa que puede fistulizarse en el exterior de la articulación para formar una bola sinovial. Se trata de un quiste artrosinovial de la muñeca. En el lenguaje popular, se habla de quiste sinovial o simplemente de quiste de la muñeca

\section{La artroscopía de muñeca}

La artroscopia de muñeca, representa "una cirugía representa una intervención con menos riesgos, pues se aplica anestesia local en el brazo y es ambulatoria". (Barclay, 2019, pág. 29). También, es una cirugía más estética ya que, para cicatrizar, solamente quedan dos orificios en comparación a una herida mayor. Otro de sus beneficios es que, al ser menos invasiva, la recuperación es más rápida, lo que permite al paciente recuperar la movilidad más rápido; y requiere la misma preparación de cualquier cirugía. (Barclay, 2019, pág. 29)

Antes de indicar tratamiento, el médico "debe tener en cuenta que la mayoría de los gangliones de muñeca son asintomáticos y que, en adultos, hasta un 60\% desaparecen de forma espontánea". (Barclay, 2019, pág. 29). El tratamiento estaría indicado en gangliones sintomáticos e inicialmente, aunque las tasas de recurrencia son mayores, sería de elección la aspiración del fluido del quiste, dada su tasa menor de complicaciones y el menor coste en relación a la cirugía abierta.

Debido a su alta complejidad, y a la aplicación de tecnología sofisticada, este tipo de operación "representa una cirugía que

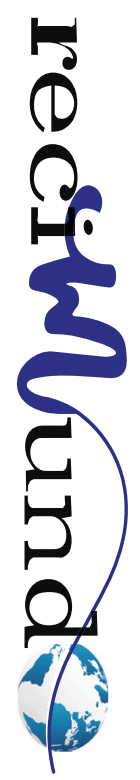


debe ser ejecutada por un médico especialista, que a su vez, debe ser asistido por un equipo multidisciplinario entrenado para este procedimiento específico (anestesista, auxiliar de rayos, arsenalero quirúrgico, etc.)". (Barclay, 2019, pág. 29) A su vez, la cirugía artroscópica permite realizar una sinovectomía articular, la cual a menudo presente en la periferia del quiste sinovial.

Se puede decir entonces que, la artroscopia de la muñeca permite disminuir la talla de la cicatriz. Según (Barclay, 2019, pág. 29), "en la mayoría de los casos sólo 2 incisiones quirúrgicas de $2 \mathrm{~mm}$ son necesarias y no necesitan puntos de sutura". Por tanto, la operación artroscópica permite igualmente realizar una sinovectomía de los extensores de la muñeca. Por todas estas razones, la cirugía artroscópica de los quistes sinoviales permite disminuir considerablemente el tiempo de recuperación de la muñeca y la convalecencia de la mano. Este tipo de cirugía, también hace posible la disminución de las molestias relacionadas con la intervención quirúrgica y los riesgos de complicaciones: hematoma, dolores en la muñeca, problemas de cicatrización.

\section{Conclusiones}

Los gangliones son tumefacciones quísticas, que surgen asociados a expensas de una articulación o una vaina tendinosa, en el dorso de la muñeca, y principalmente en la articulación escafolunar. Este tipo de lesiones, se caracterizan por tener una incidencia relativamente frecuente, sobre todo en las mujeres, por la laxitud del sistema ligamentario, y pueden generarse tras traumatismos locales en la muñeca o por microtraumatismos de repetición.

Asimismo, estos tumores se suelen encontrar entre los tendones del extensor corto y el extensor del índice. También en la cara palmar, en la corredera cubital o en el túnel del carpo, por lo que pueden llegar a ser dolorosos generando un compromiso nervioso a nivel del nervio mediano o cubital.
Los mismos, suelen ser indoloros, aunque si se encuentran en la cara palmar pueden generar molestias al forzar los movimientos de extensión de muñeca, coger peso y movimientos extremos de muñeca. No suelen presentar problemas en cuanto a la movilidad articular, salvo en casos que sean de un gran volumen o comprometan alguna estructura nerviosa. (Doris Daniela, 2016)

El tratamiento suele ser quirúrgico, pero tiende a la recidiva. Si no se encuentran síntomas dolorosos o de compromiso nervioso, mejor optar por el tratamiento conservador en un inicio, ya que las repercusiones y complicaciones derivadas de la cirugía pueden ser mayores que el propio ganglión. Cuando no son muy grandes y las paredes no están muy fibrosas, se pueden hacer maniobras de aplastamiento, que tienen como objetivo romper el quiste.

Posterior a esto, se realizan masajes y movilizaciones analíticas para asegurar la difusión del líquido. Si es muy elástico es difícil de romper, y en este caso se realizan masajes en estrella, con la posterior colocación de un vendaje compresivo con una almohadilla durante varios días para evitar las recidivas, aunque siempre pueden volver a aparecer. Si el quiste estalla, depende de la calidad del líquido que lo forme y de la capacidad de reabsorción.

\section{Bibliografía}

Arias, F. (2010). Paradigmas de la Investigación Científica. España: Editorial: Luces.

Barclay, F. (2019). Quiste Sinovial de Muñeca. Revista de Cirugía de la Universidad Nacional de México, 24-45.

Clinica Davila. (2018). Artroscopía de la muñeca: cirugía de alta tecnología con grandes beneficios. Madrid.

Dávila, G. (2010). Técnicas de recolección y análisis de Datos. España: Editorial: Sintesis.

Doris Daniela, F. (2016). Abordaje fisioterapéutico de la columna cervical baja, para el tratamiento del síndrome del túnel carpiano, en pacientes de 30 a 50 años de edad, en el centro de reha- 
bilitación integral especializado $n^{\circ} 1$. Conocoto, durante el período septiembre del 2015 -. Quito, Ecuador: Universidad Central del Ecuador. Obtenido de http://www.dspace.uce.edu.ec/bitstream/25000/11745/1/T-UCE-0020-009-2016.pdf

Martínez Roncal, R., Elena Salcedo, M., \& Salcedo, M. (2009). Correlación clínica ecográfica del quiste sinovial de mano y muñeca. Revista Médica La Paz, 15(1), 35-39. Obtenido de http://www. scielo.org.bo/scielo.php?script=sci_arttext\&pi$d=$ S1726-89582009000100005

Medline. (2018). Sobredosis de corticoesteroides. Estados Unidos, Bethesda: Biblioteca Nacional de Medicina de los Estados Unidos. Obtenido de https://medlineplus.gov/spanish/ency/article/002582.htm
Osses, E., Muñoz Ch, S., \& Astudillo A, C. (2009). Estudio por imágenes de los gangliones musculoesqueleticos. Revista chilena de radiología, 15(2), 70-77. doi:10.4067/S0717-93082009000200005

Peláez, M. (2017). Resección artroscópica de quistes sinoviales dorsales de la muñeca . Revista Argentina Artroscópica, 18.

Posada, S. (2019). Tratamiento Quirúrgico de Quiste Sinovial. REVISTA DALUS EN TABASCO EN MÉXICO, 12 - 45 .

Seguerí, M. (2016). Tratamiento Quirúrgico y complicaciones de Quistes Sinoviales. Revista de Cirugía Ambulatoria de la Universidad de la Haban en Cuba, 11-34.

\section{CITAR ESTE ARTICULO:}

Zambrano Castro, M., Orellana Rodriguez, J., Rambay Ayala, F., \& Ronquillo del Pozo, S. (2020). Tratamiento quirúrgico del quiste sinovial en muñeca. RECIMUNDO, 4(1), 296-305. doi:10.26820/recimundo/4.(1).enero.2020.296-305

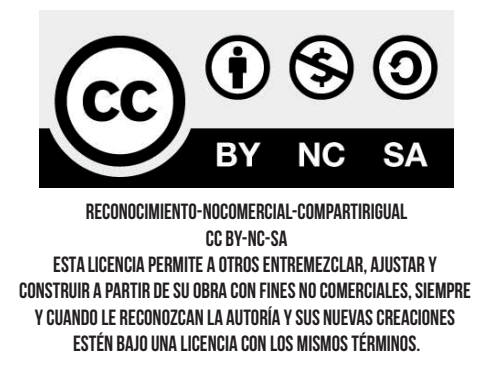

